\title{
Christian Jouhaud, Richelieu et l'écriture du pouvoir. Autour de la journée des Dupes
}

\section{Monica Pavesio}

\section{(2) OpenEdition}

\section{Journals}

\section{Edizione digitale}

URL: http://journals.openedition.org/studifrancesi/1317

DOI: $10.4000 /$ studifrancesi. 1317

ISSN: 2421-5856

\section{Editore}

Rosenberg \& Sellier

\section{Edizione cartacea}

Data di pubblicazione: 1 décembre 2015

Paginazione: $587-588$

ISSN: 0039-2944

\section{Notizia bibliografica digitale}

Monica Pavesio, "Christian Jouhaud, Richelieu et l'écriture du pouvoir. Autour de la journée des Dupes»,

Studi Francesi [Online], 177 (LIX | III) | 2015, online dal 01 décembre 2015, consultato il 08 janvier 2021. URL: http://journals.openedition.org/studifrancesi/1317 ; DOI: https://doi.org/10.4000/studifrancesi. 1317

Questo documento è stato generato automaticamente il 8 janvier 2021.

\section{(c) $($ ) $\odot$ (8)}

Studi Francesi è distribuita con Licenza Creative Commons Attribuzione - Non commerciale - Non opere derivate 4.0 Internazionale. 


\title{
Christian Jouhaud, Richelieu et l'écriture du pouvoir. Autour de la journée des Dupes
}

\author{
Monica Pavesio
}

\section{NOTIZIA}

CHRISTIAN JOUHAUD, Richelieu et l'écriture du pouvoir. Autour de la journée des Dupes, Paris, Gallimard, 2015, pp. 341.

1 Molto è stato scritto sulla "Journée des Dupes", ma sempre nello stesso modo: un giorno Richelieu viene allontanato dal potere, il giorno dopo trionfa sui suoi nemici e diventa l'uomo più potente di Francia.

2 Il libro di C. Jouhaud ricostruisce la crisi politica del 1630-1631, "le grand orage" in cui Richelieu rischia di perdere il potere e la vita, per illustrare come quello che è stato a lungo descritto come uno scatto d'ira della Regina madre nei confronti del suo ex favorito Richelieu, che viene allontanato dal potere, sia in realtà il sintomo di un conflitto politico di più lunga durata. Non si limita a descrivere la vicenda, ma studia le fonti di quell'avvenimento, ne descrive i protagonisti celebri e meno conosciuti, i vincitori e i vinti, scruta i luoghi, scopre le passioni dissimulate e i non detti. Insomma, analizza la vicenda come un fenomeno inserito in un periodo storico ben definito, chiamato barocco. Una vicenda nata e sviluppatasi in un momento contraddittorio e complesso della storia della Francia, attraversato da dinamiche di polarizzazioni (dissimulazione/ostentazione, visibile/invisibile, segreto/pubblico, silenzio/enfasi retorica), impossibili da cogliere in un'analisi unificante.

3 La "Journée des Dupes", secondo Jouhaud, non s'inserisce dunque, come vogliono gli storici, in quel clima di armonia e di perfezione detta "classica"; le fonti scritte sulla vicenda sono contraddittorie e disomogenee, possono essere confrontate, ma non montate in un discorso univoco. Lo storico non può, dunque, ergersi a direttore 
d'orchestra, con analisi e interpretazioni armoniche degli scritti relativi alla vicenda, ma deve, come in un'autopsia, sviscerare l'avvenimento, per esplorarne le ramificazioni, grazie all'analisi degli scritti voluti dal potere politico o nati in opposizione ad esso. 